\title{
Using social media to recruit global supply chain managers
}

Purpose - The purpose of the research is to investigate if, and to what degree, social media are used for the recruitment of global supply chain managers.

Design - This is a conceptual paper that discusses how organizations should engage with social media platforms for effective recruitment of global supply chain managers.

Findings - Findings are that organizations seeking to employ global supply chain managers, particularly those engaged in B2B activities, lag other industry sectors in adopting new ways of recruiting talent. Building on the findings, we present models of how organizations should move to adopt web-based technologies and the steps needed to engage fully in using social media to recruit global supply chain managers.

Research implications - Global supply chains (including logistics) lag other industry sectors in adopting social media networks for recruitment, and risk missing out on talent if the issues are not addressed. Serious consideration needs to be given, particularly by B2B but also by B2C businesses, in order to attract suitable employees. Employees' and prospective employees' expectations will increasingly revolve around the use of social media.

Originality/value - The research is original in that it investigates an emerging, contemporaneous issue that is of considerable importance in recruiting global supply chain managers. The research provides value by highlighting that in recruiting global supply chain managers, organizations have been slow to adopt new technologies, and recommends actions to remedy this.

Keywords: Global supply chain managers, recruitment, social media, B2B, B2C

Paper Type Conceptual paper

\section{Introduction}

Previous research on staffing the global organization has focused on the different capabilities and training that the global supply-chain manager of the future will need, along with the impact of national culture at its interface with organizational culture (e.g. Harvey and Richey, 2001). The growing importance of having the appropriate human resource management (HRM) processes to select, train, and retain competent global managers has also been addressed in recent research (e.g. Harvey et al., 2013). In addressing the human resource dimensions of successful global supply chain management, the growing importance of HRM in the management of supply chains is presented as a combination of resource-based (e.g. internal), market-based (e.g. external) and dynamic capabilities perspectives. In addition, selecting, training and assessing the new 'breed' of global supply-chain managers is explored (Harvey et al., 2013). A change in focus towards global supply chain managers, away from local pools of talent, has implications for how global managers are recruited in order to accommodate the cultures of emerging countries. Changes include the need for tacit knowledge, local team building, leading in dynamic environments and extensive local and social knowledge. The challenge is to fill global supply chain assignments in emerging economies (Harvey et al., 2013, p. 17). The research presented in this 
article extends the work of Harvey and Richey (2001) and Harvey et al., (2013) by considering how global supply chain managers are recruited using social media as the main means of recruitment.

With the increase in popularity of social media sites such as Facebook, Twitter and Linkedin over the past five or six years there has been a move towards using these platforms in many business sectors to manage and promote business in areas such as brand awareness, and client and partner management. More recently, organizations have extended their web presence to include employee or recruitment management. The global supply chain sector is one that has been slow to adopt new approaches to recruiting talent. In the global supply chain arena many $\mathrm{B} 2 \mathrm{C}$ organizations have a web presence but few have extended this beyond partner management to include talent acquisition. In the case of B2B even fewer organizations than in B2C have extended their web presence to embrace the client and partner markets. As using social media for recruitment usually builds on platforms for client and partner management, it follows that few B2B organizations use social media to attract talent.

In the study we investigate if, and to what degree, social media are used for recruitment of global supply chain managers. The research is important as in it we address an emerging area of importance for organizations, with a focus on global supply chain managers. Chauhan et al., (2013 forthcoming) predict that human resource departments will increase their use of social networks over time. Major factors in the increase in the use of social networks are convenience and reduced costs for organizations. To date there is little research that studies the impacts of using social media for recruitment and selection at either the organizational or individual level (Chauhan et el., 2013). In this study we also propose ways in which organizations progress to using social media for recruitment (Alf, 2013), together with a best-practice model of planning, implementing and maintaining a social media platform for recruitment (Lumesse, 2011; Madia, 2011).

First we review the academic and practitioner literature relating to the use of social media for recruitment. Second, we consider the impact of social media recruitment practices on global supply chain managers. Third, we propose a model of how organizations progress from a web presence to use of social media for recruitment. Finally, we propose a best-practice model for conceptualizing, implementing and maintaining a social media platform for recruitment.

\section{Literature review}

Harvey and Richey (2001) and Harvey et al., (2013) focus on the challenges of selecting, training and appraising global supply chain managers, arguing that global managers are difficult to identify and attract (Bartlett and Ghoshal, 2003; Harvey et al., 2013). Managing global supply-chain businesses involves collaboration with stakeholders on a worldwide rather than local basis. However, the traditional pool of managers available for overseas assignments often does not contain an adequate supply of persons capable of meeting an organizations' needs for staffing in emerging and transition markets (Bartlett and Ghoshal, 2003; Kiessling, Harvey and Garrison, 2004; Harvey et al., 2013). Therefore, there is a pressing need for alternative pools of candidates to be developed in order to ensure an adequate supply of global supply chain managers (Harvey and Richey 2001).

While selecting, training and appraising global managers are critically important issues for organizations, what is axiomatic is how the global managers of the future will be recruited. The traditional ways of recruitment (e.g. newspaper advertisements, trade fairs, job boards) will no longer be sufficient, and new approaches will be 
needed (Alf, 2013). It is predicted that persons born during the 1980s (Gen Y) will make up about three quarters of the world's workforce by 2025 (Samuelson, 2012). Following behind Gen Y, and still to enter the workforce, are persons born since 2000 (Gen Z). It will be an assumption of members of both Gen $Y$ and Gen $Z$ that businesses will use social media as a means of addressing the client, partner and employee markets (Alf, 2012).

Since social networking sites allowed organizations to create web profiles many businesses have incorporated a social media web presence into their marketing and management programs (Waters et al., 2009). Uptake in the use of social media by business has been spurred by the realization that social media are a new and important part of the promotion mix, where one person has the power to communicate with many others about products and services (Mangold and Faulds, 2009; Patterson, 2012). In the not-for-profit sector organizations have mainly used social media for public relations, while for-profit organizations have tended to use them for product launches and brand management (Waters et al., 2009). A factor that has increased the use of social media by business is the finding that users, particularly Gen Y, not only use social media to share opinions but also appear to be affected by these opinions in the ways they perceive brands, businesses and organizations (Rai, 2012). As a result the adoption of social media in the for-profit business sector has grown substantially over recent years, with companies increasingly using social media tools such as Facebook and Twitter to interact with customers, manage brands and for employee engagement (He et al., 2013). As a result, a large amount of business material is readily available on social media sites. Increasing amounts of information in the public domain pose challenges to organizations in monitoring and analyzing the content of their own social media sites, and those of competitors (He et al., 2013). Recent research suggests that the reasons for increasing trends in societal use of social media include activities such as making new friends, socializing with old friends, receiving information, and entertaining (He et al., 2013; Golbeck, 2013; Kaplan and Haenlein, 2010). Consequently, many organizations are adopting social media in order to impact business values (Culnan et al., 2010) by increasing customer numbers and brand loyalty (Di Gangi et al., 2010), improving customer satisfaction, retaining customers, and building organizational reputation (He et al., 2013; Golbeck, 2013; Kietzmann et al., 2011; Weber, 2009). While many organizations recognize the need for active use of social media, achieving this effectively, including understanding what to do and how it should be measured, is often elusive (Hanna et al., 2011). While social media provides a powerful platform for organizations, many executives are unable or unwilling to develop strategies that engage effectively with it (Kietzmann et al., 2011).

In research by Chauhan et al., (2013 forthcoming) it is predicted that human resource departments will increase their use of social networks over time. Major factors in the increase in use are convenience and reduced costs for organizations. There is a growing trend in some industries (e.g. hospitality) to use social networking sites for recruitment (Madera, 2012). In a study of recruiting practices in hospitality, Madera and Chang (2011) found that although the initial purpose for developing a social network was for customer service and marketing, networks had further developed for recruitment purposes. Madera (2012) found that some organizations were also using social media for employee selection, a process that caused concerns for a large proportion of users. There is clearly a difference in using social networking for recruitment, which we consider in this paper, and using it for selection or screening. Chauhan et al., (2013) argue that there is little research that studies the 
impacts of using social media for recruitment and selection at either the organizational or individual level. In response to a shortage of research in the area this paper aims to address the use of social media for the recruitment of global supply chain managers.

\section{Using social media for recruitment}

Caers and Castelyns (2011) argue that Facebook and LinkedIn are mainly used for different purposes and in different contexts. Facebook allows friends to connect, to share personal information, and to meet new people (Papacharissi, 2009). LinkedIn allows professionals to connect, to market skills, to share knowledge and experiences, and to plan future career steps (Trusov et al., 2009). Both platforms provide a suitable means for updates on developments in other organizations and for making professional appointments (Caers and Castelyns, 2011). Research suggests that persons who use LinkedIn frequently may receive benefits in an active recruitment setting (Caers and Castelyns, 2011). Frequent users appear to have discovered this, while occasional users may not use accounts sufficiently frequently to experience or create the benefit. Facebook seems to be less frequently used for active recruitment. However, respondents agree that both LinkedIn and Facebook may not be suited for internal recruitment with few respondents actually having used them so far in this context (Caers and Castelyns, 2011).

There are almost one billion (Facebook, 2013) and 200 million (LinkedIn, 2013) users in 2013. In a 2010 survey of social media use by corporate recruiters, 83 percent of respondents indicated they currently use or are planning to use social media for recruitment (Lumesse, 2011). Of the social media platforms available LinkedIn is the network of choice for recruitment, with 86 percent of respondents citing this as the preferred medium (Madia, 2011). LinkedIn is also the leading source for successful appointments, though Facebook and Twitter have also emerged as viable recruitment channels. Madia (2011) also reports that despite the global economic turndown the number of dedicated recruitment sites has increased. For many recruiters, social media have become part of a more cost-effective recruitment approach and a faster way to get employment opportunities posted to meet timeframes that the recruiter controls. Recruiters can send and resend job opportunities as often as deemed necessary, while minimizing spend on more traditional, complementary ways of recruitment (e.g. job boards).

\section{Strategies for engagement}

Despite the appeal and relative ease of use, using social media for recruitment presents challenges for organizations. Human resource department staff who are not well prepared for engaging candidates often find themselves swamped by applications. Large numbers of applications demand well formulated processes and well trained staff to deal with them. Failure to be well prepared allows well qualified potential candidates to escape the net. Madia (2011) offers a set of 'best practice' points, which she recommends for recruiters new to using social media: 1) understand that social media complements rather than replaces traditional means of recruitment; 2) ensure your corporate web site is up to date and able to handle additional volume; 3 ) ensure adequate resources; 4) provide timely responses appropriate to the medium;

5) formulate a social media policy; 6) from the policy prepare a plan with business objectives; 7) select the social networks that are most closely aligned with your target audience (LinkedIn will be the first network for most businesses); and 8) consider 
producing a video and using You Tube for dissemination. This allows a business to project a desired image and informs potential job seekers of company culture etc.

Madia (2011) also argues that despite widely varying levels of awareness, adoption, and understanding among human resource recruiters, social media is a growing means of recruiting due to traditional ways being less effective than they were. An on-line presence is much cheaper than newspaper advertising or job fairs and even organizations that prefer traditional ways of recruiting should be considering social media. A good place for skeptical businesses to start is by looking at what the competition is doing. Madia (2011, p. 23) argues, “...the key is to create a wellthought plan before engaging in the space, ensure that you are adequately resourced, start small, and use knowledge gained to further fine tune and optimize your online recruitment strategy."

Doherty (2010) suggests that while early suspicions of social networking sites have abated, organizations are now embracing social networking as a way to attract and retain employees. This has led to many organizations now creating online presences using the likes of LinkedIn, Twitter and Facebook, in order to engage with candidates and give them the opportunity to interact with them on a more informal basis. Others are creating career web sites to commence discussions with candidates and encourage them to look at potential vacancies and then apply. There is little doubt that the use of social media gives organizations an effective means of attracting today's Generation Y workforce (Doherty, 2010, p 11).

In other research Otter (2009) suggests that recruitment is an ideal starting point for social media usage in HR because key metrics, such as time to hire and cost of hire, can be measured and improvement can be substantiated (Otter, 2009). In addition, as the workforce ages, businesses need to become more competitive in order to attract and retain the new generation of young, enthusiastic workers. This is because they make the organization's brand stand out from the crowd by showing that it is staying relevant and embracing change as technology and ways of communicating evolve (Doherty, 2010).

\section{Recruitment of global supply chain managers}

While the use of social media is changing the ways in which businesses operate, it is not as prominent in the area of global supply chains, and in particular recruitment of global supply chain managers, as it should be (Alf, 2013). From an uptake of technology perspective supply chain management is behind retail (Alf, 2013), IT, engineering, sales and marketing in the use of social media (Lumesse, 2011).

Global supply chain organizations use social media to address issues in three main areas: the client market, the partner market and the employee market. In the client market the use of social media has a long-term future in providing interactions and communications much in the way that the telephone or the facsimile did in the past. In the partner market supply chain businesses are using social media to build partnerships with suppliers, to listen to supplier's concerns and to monitor relationships. In the employee market future employees are very active in their use of social media, and it is the expectation of Gens $\mathrm{Y}$ and $\mathrm{Z}$ that business will be conducted via these means. In the future global supply chain organizations will need to be active in the use of social media in order to win talent (Alf, 2013). In this research we argue that the use of social media for recruitment of global supply chain managers tends to occur only after a organization has developed a web presence as a means of communicating its brand, then built on its brand to address the client market, then developed further to address issues in their partner market, as shown in 
diagram 1. It appears from recent research (e.g. Alf, 2013; Lumesse, 2011) that few global supply chain organizations have progressed to the point where they can address the employee market.

Take in Diagram 1 about here

For global organizations providing B2C services, where the Internet potentially influences an estimated $80 \%$ of decisions, a social media presence is an imperative to manage customers, reflecting the direct connections of this sector with the consumer market (Alf, 2013). An example of the rapidly changing B2C market is call centers that over a four-year period experienced an increase from a base of four to forty percent of contact received via social media (Alf, 2013), leading to a reduction in the number of centers. Examples of predominantly B2C companies that have embraced the use of social media include: 1) Fedex with a substantial Facebook and Twitter following - 135,000 Twitter followers, 60,000 employees - two thirds of whom are on LinkedIn; 2) UPS with 90,000 on LinkedIn; and 3) DHL with 82,000 followers on Facebook and 108,000 on LinkedIn (Alf, 2013).

For global organizations providing B2B services the need for a social media presence is less of an imperative given the business environment in which they operate. Nevertheless B2B organizations will need to engage fairly soon. There are fewer examples of businesses engaging with social media in this sector but Freightliner is one. Freightliner has an outstanding social media presence, with 47,000 Facebook followers, which it uses as a means of community building. Despite the success of a handful of organizations, few have developed a web presence sufficiently to use it as a platform for recruitment (Alf, 2013).

Global recruiter Lumesse (2011) suggests that social media has become an essential recruitment tool for employers and employees alike. For organizations it offers a most effective medium for employers to promote their brand to potential talent. Many organizations also use social media to build internal communities for existing staff, to spread news, share expertise and celebrate success. For potential employees social media provides a unique opportunity to gather intelligence about prospective employers by interacting with potential peers. In this way people who otherwise might never meet until after an exhaustive interview process are instantly available online. Social media also provide a way to reach out to people who may not be active in the job market, but who might be tempted by the right opportunity (Lumesse, 2011).

Social media recruiting involves either a business advertising a vacancy and receiving applications from network users or by means of 'headhunting' individuals through their postings on media such as Facebook and Linkedin. From worldwide research conducted in 2010 involving over 300 people in senior recruitment or management roles Lumesse (2011) established that 60 percent of businesses surveyed currently use social media for recruiting talent. Of the remaining 40 percent, two thirds indicated that they would be investigating using social media for recruitment in the near future. Lumesse (2011, p. 3) concludes, “... social media may be considered a standard tool of talent acquisition for many organizations." However, there are still many employers who neither use nor plan to use social media for recruitment purposes in the future. Global organizations are represented to a high degree in this group of businesses. Research suggests that almost seven in ten companies cite a lack of knowledge of social media, while the remainder suggest that company policies banning or restricting access to social networking sites are to blame. 
Social media platforms meet a number of employer needs. Lumesse's (2011) research identifies that three-quarters of social media users regard branding as a key purpose, with talent acquisition a beneficiary of general marketing messages. Also, more than three in five use social media to directly search for new hires. More than half of respondents state that they use social media to keep in contact with people who are not actively looking for employment but who might apply at a later date. More than four in ten companies promote specific vacancies using social media. Social media are predicted to attract greater investment in the future. Given that the survey shows that many organizations don't yet regard social media as one of their top three recruitment channels, this reinforces its rising importance for those who do recognize it. However, the relatively recent emergence of social media may slightly skew these results. In companies, which have invested little in social media to date, even smallish budget allocations might represent a significant increase. A greater tendency to rely on in-house solutions may also explain why social media recruitment might attract greater expenditure in future, alongside corporate career sites (Lumesse, 2011, p. 6).

As Harvey et al., (2013) point out the change in focus to global supply chain managers, away from local pools of talent, has implications for how global managers are recruited to accommodate the cultures of emerging countries, including the need for tacit knowledge, local team building, leading in dynamic environments and extensive local and social knowledge. The challenge is to fill global supply chain assignments in emerging economies. In terms of global supply chain recruitment social media has been a less widely used platform than in industries such as IT, engineering, executive recruitment, sales and marketing (Lumesse, 2011). The nature of the supply chain sector, with its large B2B component, may explain why organizations have engaged with the use of social media to a lower degree than other industries. While many global and domestic organizations recognize the value of a web presence from the perspective of brand management, many have not taken advantage of the benefits of client, partner and employee connections that social media offer. Global supply chains will undoubtedly miss out on talent in the future unless there is move towards using social media for more than just brand management.

\section{Achieving effective global supply chain recruitment using social media}

Guided by the progression from developing a web presence for brand management to using social media for global supply chain recruitment, the steps in planning, implementing and maintaining a social media platform for recruitment are now discussed, and are shown at Diagram 2 below. The first step is to develop a social media recruitment strategy. Lumesse (2011) suggests that in developing a strategy, organizations will need to consider how using social media integrates with existing approaches to recruitment, retention and wider business objectives. It is essential for

Take in Diagram 2 about here

organizations to understand why they are using social media by asking questions like: 1) what does the employer brand look like; 2) how can we reflect the desired brand using social media; 3 ) how do we want our social media activity to influence what potential recruits think of us; 4) who do we want to meet through social media; and 5) what are potential employees seeking? Global supply chain businesses wishing to obtain the benefits of sourcing talent through the use of social media should consider Lumesse's (2011) 4Cs approach to social media use, which is: 1) communication - by 
making regular contributions to the networks you join so that people get to know you; 2) collaboration - making your own contribution to discussion and ideas but also being willing to listen and work in partnership with others; 3) conversation participating in the organization's digital scene by interacting through the use of conversations, blogs etcetera; and 4) community - finding people who share a common interest on specific issues, such as your business' products or services and maintaining the company profile.

\section{Discussion}

Previous research has shown the importance of selecting and training global supply chain managers (Harvey and Richey 2001; Harvey et al., 2013). This paper extends research on global selection and training by considering how global supply chain managers are recruited using social media as the main means of recruitment. The importance of employing appropriate people in global assignments is well-known, yet literature shows that in the critical area of recruitment global supply chain businesses risk missing out on key management staff due to a failure to engage with emerging recruitment approaches based on social media (Alf, 2013). The research (Alf, 2013) suggests that businesses move from a web presence as a brand management tool, through client and partner management to recruitment. The issue in global supply chains appears to be that while many organizations have established a web presence many in the $\mathrm{B} 2 \mathrm{~B}$ sector have not progressed past the brand management stage of web usage. In the case of B2C organizations more may have developed client management systems, and in some cases partner management systems, but few have engaged with social media recruitment. The dangers for organizations not using social media for the recruitment of global supply chain managers include the likelihood that they will miss out on key talent, which will compound the challenges of managing in global and emerging markets discussed in previous research (e.g. Bartlett and Ghoshal, 2003; Kiessling, Harvey and Garrison, 2004; Harvey et al., 2013). Talent that may have been employed as global supply chain managers will likely be employed elsewhere.

Global organizations must realize that in order to be competitive in the market they need to employ key talent, which in turn makes building a viable web presence necessary. In most cases the progression from brand management to social media recruiting will follow the steps advocated by Alf (2013) as set out in diagram 1. It is unlikely that a global organization will embrace social media recruiting without first developing a web presence that promotes and manages brand, clients and partners. Having got to the stage where consideration is being given to using social media for recruitment, we suggest ways in which the planning, implementation, and ongoing monitoring and maintenance could be achieved, as set out in diagram 2 .

The challenge is to recruit appropriate global supply chain managers in order to minimize the environmental difficulties facing organizations in complex and emerging markets. It is well documented (e.g. (Bartlett and Ghoshal, 2003; Kiessling, Harvey and Garrison, 2004; Harvey et al., 2013) that global businesses depend on sourcing and retaining key staff to a much greater degree than those at a national level. Unless global organizations recruit the most appropriate supply chain managers they run the risk of failing to achieve optimum performance. Recruiting the most appropriate staff will increasingly depend on using social media as a recruitment tool.

\section{Implications for management and further research}

Implications for management include recognizing the challenges involved in staffing global supply chains, as set out in Harvey et al., (2013, p. 17). Having recognized the 
need to generate a pool of suitable applicants, organizations will need to quickly adopt social media as the recruitment tool of choice, given that it is the preferred means of communication for what will soon be the majority of workers (Alf, 2013; Doherty, 2010; Samuelson, 2012). Failure to embrace the use of social media for recruitment has the potential to negatively affect organizational performance through sub-optimal appointments.

Opportunities for further research include: 1) testing the best-practice model with empirical research; 2) research in other industries to ascertain how social media are used for staffing, and whether these approaches are effective; and 3) extending the research of Chauhan et al., (2013 forthcoming) to establish the attitudes of global supply chain managers to the use of social media for recruitment.

\section{Conclusion}

The present study addresses an under researched area involving recruitment of global supply chain managers, in the context of success or failure of global businesses. Global organizations, particularly those engaged in B2B business, have been slow to adopt new and emerging approaches to talent acquisition based on the use of social media. As a consequence organizations face the prospect of missing out on talent in their search for effective global supply chain managers. While B2C businesses have adopted a more proactive approach to the use of web-based technologies few have taken the additional step to embrace social media recruiting.

The research presents the steps that a global organization follows in moving to adopt a social media recruitment platform, through a theoretical model, based on recent research by Alf (2013). The research also presents a best-practice model of conceptualizing, implementing and maintaining a social media recruitment platform based on recent academic (Madia, 2011) and global practitioner research (Lumesse, 2011).

\section{Acknowledgements}

The authors wish to acknowledge the assistance of Lumesse Pte Ltd, Singapore in the development of this paper.

\section{References}

Alf, M. (2013), "Social media in logistics: Nice to have or a pre-requisite for success" Retrieved March 20, 2013 from: www.cilta.com.au/Content/Attachment/ SocialMediaWebinarRecording 150213.wmv

Bartlett, C., and Ghoshal, S. (2003), "What is a global manager?" Harvard Business Review, Vol. 81 No. 8, pp.101-108.

Caers, R., and Castelyns, V. (2011), "LinkedIn and Facebook in Belgium: The influences and biases of social network sites in recruitment and selection procedures", Social Science Computer Review, Vol. 29 No. 4, pp. 437-448.

Chauhan, R., Buckley, M., and Harvey, M. (2013), "Facebook and personnel selection: What's the big deal?", Organizational Dynamics,

Culnan, M., McHugh, P., and Zubillaga, J. (2010), "How large U.S. companies can use twitter and other social media to gain business value", MIS Quarterly Executive, Vol. 9 No. 4, pp. 243-259.

Di Gangi, P., Wasko, M., and Hooker, R. (2010), “Getting customers' ideas to work for you: Learning from Dell how to succeed with online user innovation communities", MIS Quarterly Executive, Vol. 9 No. 4, pp. 163-178. 
Doherty, R. (2010), "Getting social with recruitment", Strategic HR Review, Vol. 9 No. 6, pp. 11-15.

Facebook. (2013), Statistics. Retrieved March 18, 2013, from http://www. facebook.com/press/info.php?statistics

Golbeck, J. (2013) Analyzing the social web, Morgan Kaufman, Waltham, MA.

Hanna, R., Rohm, A., and Crittenden, V. (2011), "We're all connected: The power of the social media ecosystem”, Business Horizons, Vol. 54, pp. 265-273.

Harvey, M., Fisher, R., McPhail, R., and Moeller, M. (2013), "Aligning global organizations' human capital needs and global supply-chain strategies", Asia Pacific Journal of Human Resources, Vol. 51 No. 1, pp. 4-21.

Harvey, M., and Richey, R. (2001), "Global supply chain management: The selection of globally competent managers", Journal of International Management, Vol. 7, pp.105-128.

He, W., Zha., S., and Li, L. (2013), "Social media competitive analysis and text mining: A case study in the pizza industry", International Journal of Information Management, Vol. 33, pp. 464-472.

Kaplan, A., and Haenlein, M. (2010), "Users of the world, unite! The challenges and opportunities of social media", Business Horizons, Vol. 53 No. 1, pp. 59 - 68.

Kiessling, T., Harvey, M., and Garrison, G. (2004), "The role of boundary spanners in global supply chains in the 21st century", Journal of Global Marketing, Vol. 17 No. 4, pp. 78-89.

Kietzmann, J., Hermkens, K., McCarty, I., and Silvestre, B. (2011). "Social media? Get serious! Understanding the functional building blocks of social media", Business Horizons, Vol. 54, pp. 241-251.

LinkedIn. (2010), "Statistics", Retrieved on March, 18, 2013, from http://press.linkedin.com/about

Lumesse (2011), "Social media: The next opportunity for talent-seekers", Retrieved March 17, 2013 from: http://www.lumesse.com/media/983455/lumesse insightpaper_talentacquisition_socialrecruiting_enuk.pdf

Madera, J. (2012), "Using social networking websites as a selection tool: The role of selection process fairness and job pursuit intentions", International Journal of Hospitality Management, Vol. 31, pp. 1276-1282.

Madera, J., and Chang, W. (2011), "Using social network sites to investigate employees in the hospitality industry, Proceedings of the Annual Meeting of the International Council on Hotel, Restaurant and Institutional Education, Denver, CO.

Madia, S. (2011), "Best practices for using social media as a recruitment strategy", Strategic HR Review, Vol. 10 No. 6, pp. 19-24.

Mangold, W., and Faulds, D. (2009), "Social media: The new hybrid element of the promotion mix", Business Horizons, Vol. 52, pp. 357-365.

Otter, T. (2009), "The business impact of social computing: real-world results for recruitment", Gartner database.

Papacharissi, Z. (2009), "The virtual geographies of social networks: A comparative analysis of Facebook, LinkedIn and ASmallWorld", New Media \& Society, Vol. 11, pp. 199-220.

Patterson, A. (2012), "Social-networkers of the world, unite and take over: A meta introspective perspective on the Facebook brand", Journal of Business Research, Vol. 65, pp. 527-534.

Rai, S. (2012), "Engaging young employees (Gen Y) in a social media dominated world: Review and retrospection, Social and Behavioral Sciences, Vol. 37, pp. 
257-266.

Samuelson, K. (2012), "Making the workplace appealing to Gen Y", The Chicago Tribune, February 5, 2012.

Trusov, M., Bucklin, R. E., and Pauwels, K. (2009), "Effects of word-of-mouth versus traditional marketing: Findings from an internet social networking site", Journal of Marketing, Vol. 73, pp. 90-102.

Waters, R., Burnett, E., and Lucas, J. (2009), "Engaging stakeholders through social networking: How nonprofit organizations are using Facebook", Public Relations Review, Vol. 35, pp. 102-106.

Weber, L. (2009), Marketing to the social web: How digital customer communities build your business (2nd ed.). Wiley, Hoboken, NJ. 
Diagram 1: Global logistics organization's web presence evolving from brand management to social media recruitment

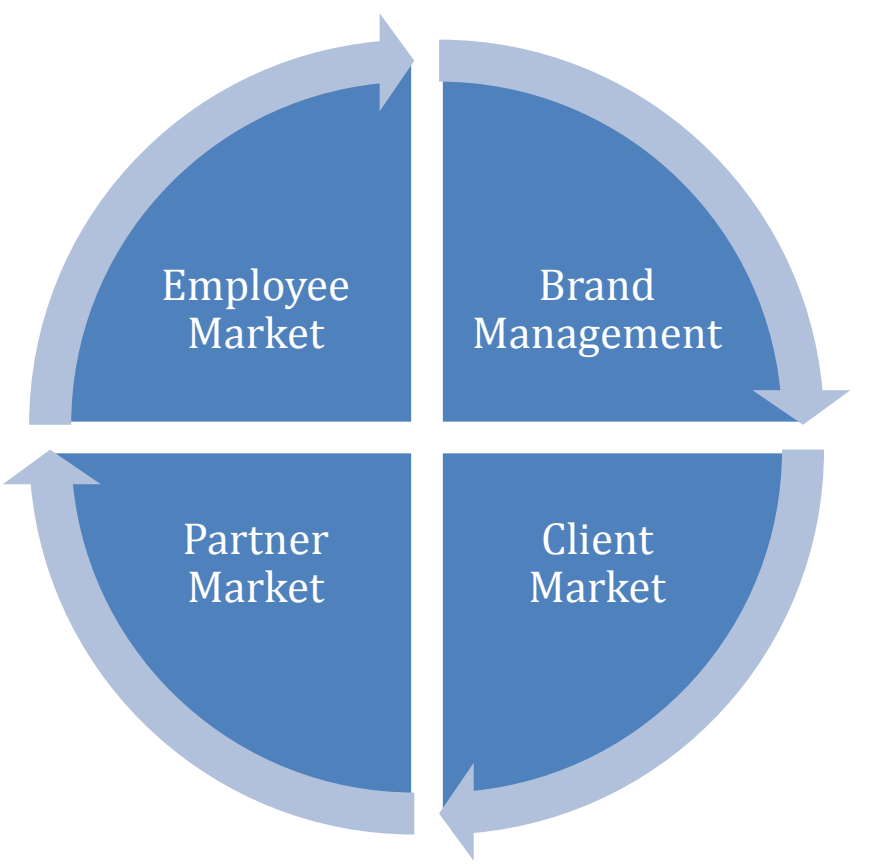

Adapted from Alf (2013) 
Diagram 2: A best-practice model for conceptualizing, developing and maintaining a global logistics social media recruitment platform

\section{Conceptualize \\ What does the \\ employer brand look \\ like? \\ - How can we reflect \\ the desired brand \\ using social media? \\ - How do we want our social media activity \\ to influence what potential employees think of us? \\ - Who do we want to meet? \\ - What are potential employees seeking?}

Lumesse 2011

\section{Construct}

- Additional source of recruitment not

replacement

- Website in order and capable

- Adequate resources

- Timely responses

- Social media policy developed

- Business objectives clearly related

- Select medium

- Promote via social media

Madia 2011

\section{Commission}

- Communication

- Collaboration

- Conversation

- Community

Lumesse 2011 